\title{
Performance of Erythorbic Acid as an Oxygen Scavenger in Thermally Aged Lean MEG
}

\author{
Ammar Al Helal ${ }^{1,2 *}$, Adam Soames ${ }^{1}$, Rolf Gubner ${ }^{1}$, Stefan Iglauer ${ }^{3}$, Ahmed Barifcani ${ }^{1}$ \\ ${ }^{1}$ WA School of Mines: Minerals, Energy and Chemical Engineering, Curtin University, Perth W.A., Australia \\ ${ }^{2}$ Al-Khawarizmi College of Engineering, University of Baghdad, Jadriyah, Baghdad, Iraq \\ ${ }^{3}$ Petroleum Engineering Department, Edith Cowan University, Joondalup W.A., Australia \\ * Corresponding Author
}

\begin{abstract}
The objective of this work is to further evaluate the performance of the erythorbic acid oxygen scavenger designed by (Kundu and Seiersten, 2017) within 85\% wt. Thermally Aged Lean Mono Ethylene Glycol (TALMEG). Experiments were performed at two levels of dissolved oxygen concentrations including 1000ppb and $>7500 \mathrm{ppb}$ at $\mathrm{pH}$ values of 6,9 and 11. Furthermore, the erythorbic acid oxygen scavenger was evaluated under conditions representative of an industrial MEG regeneration system in terms of salt and organic acid concentrations to replicate field usage. Strong performance of erythorbic acid in combination with manganese and diethylethanolamine (DEAE) was observed under field conditions suggesting that erythorbic acid may provide an attractive alternative oxygen scavenger for use in the oil and gas industry in place of traditional sulfite based scavengers.

However, the results generated within TAL-MEG showed a reduction in the performance of erythorbic acid oxygen scavenger when compared to fresh MEG solution. Moreover, results confirmed that varying acetic acid concentration did not affect oxygen scavenger performance within TAL-MEG. It was observed that the $\mathrm{pH}$ of the solution was the primary factor in determining the performance of the erythorbic oxygen scavenger tested with insufficient oxygen removal achieved at a $\mathrm{pH}$ of 6 . In contrast, strong performance was achieved at $\mathrm{pH} 9$ and 11 successfully reaching below 20ppb dissolved oxygen concentration within a reasonable timeframe with little to no impact due to the presence of mineral salt ions and organic acids.
\end{abstract}

Keywords: Oxygen Scavenger, Mono-Ethylene Glycol, Salts, Corrosion, Erythorbic Acid

\subsection{Introduction}

Mono Ethylene Glycol (MEG) is well known in the oil and gas industry as a hydrate inhibitor by controlling gas hydrate formation profile (AlHarooni et al., 2015; AlHarooni et al., 2016; Baraka-Lokmane et al., 2012; Halvorsen et al., 2007; Joosten et al., 2007; Sandengen, 2006). MEG is favoured as an alternative gas hydrate inhibitor in place of methanol and ethanol due to its high thermal stability, non-flammable nature with a high flash point and relatively lower solubility in the gas phase (Bikkina et al., 2012; Lehmann et al., 2014; Lu et al., 2010). To achieve continuous gas hydrate inhibition and sustained flow assurance, the continual dosage of MEG solution is required. In such systems, MEG solution is often regenerated to minimize operational costs and inventory requirements (Lehmann et al., 2014; Sandengen, 2006; Yong and Obanijesu, 2015). To recover MEG at a concentration suitable for reinjection back into hydrocarbon transportation pipelines (typically above $80 \%$ wt.), regeneration occurs using onshore or topsides facilities to remove excess water and contaminants including 
mineral salt ions (Flaten et al., 2015; Halvorsen et al., 2007; Joosten et al., 2007; Pojtanabuntoeng et al., 2017; Sandengen, 2006).

However, during the regeneration process if MEG is exposed to high temperatures and/or excessive oxygen levels degradation of the MEG may occur (AlHarooni et al., 2015; AlHarooni et al., 2016; Kundu and Seiersten, 2017; Yong and Obanijesu, 2015). The thermal degradation of MEG may result in the formation of organic acids including glycolic, acetic and formic acids. These organic acids represent a limitation in the number of MEG regeneration cycles that can be performed before replacement is required (AlHarooni et al., 2015; Haque, 2013; Nazzer and Keogh, 2006) if the build-up is not being otherwise managed by removal of the organic acids from the closed glycol loop on a continuous basis. Numerous studies in the oil and gas industry have been conducted to evaluate the effects of MEG thermal aging on various operational parameters, such as regeneration temperature (AlHarooni et al., 2016; King et al., 2017), pH (Clifton et al., 1985; Rossiter et al., 1985), organic acid formation (Clifton et al., 1985; Rossiter et al., 1985), corrosion rate (AlHarooni et al., 2016; Rossiter et al., 1985), gas hydrate thermodynamics (AlHarooni et al., 2015) and oxidation of MEG in the presence of metals (Brown et al., 1987; Rossiter et al., 1985). However, the performance of oxygen scavengers in the presence of TAL-MEG solutions has received little to no attention.

Furthermore, during the production of natural gas, the breakthrough of formation water is expected leading to the introduction of monovalent and divalent mineral ions into the MEG regeneration system (AlHarooni et al., 2015; Babu et al., 2015; Halvorsen et al., 2007; Sandengen, 2006). The ratio of divalent cations to bicarbonate or sulfate ions plays a crucial role in determining how scale formed inside pipelines and on the top of hot surfaces (Al Helal et al., 2017; Lu et al., 2010). Moreover, the presence of mineral salts in large quantities can pose significant operational constraints during MEG regeneration due to their tendency to cause scaling at elevated pH and temperature (Babu et al., 2015; Kan et al., 2005; Kan et al., 2003). Likewise, the introduction of organic acids including acetic, propanoic and butanoic can occur through the condensed water phase if such acids are present within the reservoir (Latta et al., 2013; Lehmann et al., 2014). The presence of contaminants such as salts and organic acids have been found to influence the performance of certain oxygen scavengers, with sulfite-based oxygen scavengers being particularly affected by organic acids (Finkbeiner and Bush, 1968; Salasi et al., 2017). According to several studies, organic acids including acetic acid may inhibit sulfite oxygen scavenger performance through interaction with transition metals including manganese that is used to catalyze the oxygen removal reaction (Brandt and Van Eldik, 1995; Kotronarou and Sigg, 1993; Nurmi et al., 1982; Salasi et al., 2017).

The prevention of corrosion in pipelines and process equipment is an important aspect of the continued operation of MEG regeneration facilities and transportation pipelines. Various methods of corrosion mitigation for natural gas pipelines can be applied depending upon the level of formation water within the system (Halvorsen et al., 2007; Pojtanabuntoeng et al., 2017; Salasi et al., 2017). Where formation water breakthrough has not occurred, corrosion mitigation through $\mathrm{pH}$ stabilization is typically performed through addition of basic chemicals such as $\mathrm{NaOH}, \mathrm{KOH}$ or Methyldiethanol Amine (MDEA) to promote the formation of protective iron carbonate scale (Dugstad and Seiersten, 2004; Halvorsen et al., 2007; Ivonye et al., 2015; Lehmann et al., 2014; Pojtanabuntoeng et al., 2017). However, if formation water is produced and mineral salt ions are present, the application of Film-Forming Corrosion Inhibitors (FFCIs) is necessary to avoid issues associated with scaling at 
elevated pHs (AlHarooni et al., 2016; Lehmann et al., 2014; Pojtanabuntoeng et al., 2017). Furthermore, the presence of oxygen in even minute amounts can also pose a corrosion risk to transportation pipelines and subsea systems constructed using corrosion resistant alloys (CRA) (Joosten et al., 2007; Lehmann et al., 2014; Mansoori et al., 2013).

Kundu and Seiersten (2017) stressed the importance of controlling the oxygen level in the injected MEG solutions to prevent several problems including the degradation of MEG, and general corrosion. To prevent oxygen-based corrosion issues in MEG system, oxygen in even minute amounts must be removed (Joosten et al., 2007; Salasi et al., 2017) if present in the MEG. Various studies have proposed that the acceptable level of remaining oxygen in the MEG solution must be below 20ppb to eliminate the risk of oxygen corrosion of subsea CRA equipment (AlHarooni et al., 2015; AlHarooni et al., 2016; Joosten et al., 2007; Kundu and Seiersten, 2017; Lehmann et al., 2014; Salasi et al., 2017). Oxygen intrusion into MEG systems can occur via oxygen saturated chemicals and leakages in the units that operate under vacuum such as MEG reclaimers (AlHarooni et al., 2016; Kundu and Seiersten, 2017; Pojtanabuntoeng et al., 2017). Additionally, industrial nitrogen may contain up to 3-5 mol. \% oxygen, which poses a contamination source to the lean MEG if used for storage tank blanketing (Lehmann et al., 2014; Olsen, 2006). Oxygen-scavenging chemicals may then be added to reduce the possibility of corrosion by reducing the residual dissolved oxygen concentration to acceptable levels (Kundu and Seiersten, 2017; Lehmann et al., 2014; Salasi et al., 2017).

Oxygen scavenger chemicals commonly utilized in industrial applications (specifically for water treatment and the food industry) are sulfites, bisulfites, metabisulfites, hydroquinone, hydrazine, and erythorbic acid (Abbadi et al., 2003; Amjad, 2010; Crovetto et al., 2011; Crowe, 1985; Gui et al., 2013; Kundu and Seiersten, 2017; Salasi et al., 2017). May (1989) stated that erythorbic acid (D-isoascorbic acid) could scavenge oxygen rapidly at high temperatures and pressures (boiler conditions). Furthermore, ascorbic acid (L-ascorbic acid) has also been investigated and recommended as an antioxidant in food industries due to its rapid reaction with oxygen (Christensen and Steimel, 1990; Kramarenko et al., 2006). Ascorbic acid is structurally similar to erythorbic acid, but has greater thermal stability, making it preferable for use in chemical industries at high temperatures (Nimse and Pal, 2015) (see Fig. 1).

Erythorbic acid

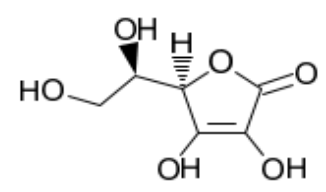

Ascorbic acid

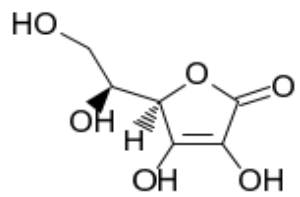

Dehydroascorbic acid

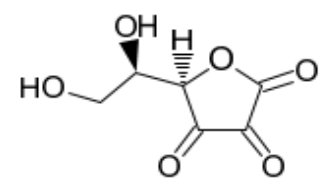

Fig. 1. Chemical structure difference between erythorbic acid, ascorbic acid and dehydroascorbic acid (Nimse and Pal, 2015)

The viability of erythorbic acid in MEG systems will be further evaluated due to its strong oxygen removal performance in other industries. The aim of this work is to further study the performance of erythorbic acid (Disoascorbic acid) to scavenge oxygen in lean MEG. The study is conducted under similar field conditions and compositions found in an industrial MEG regeneration plant with particular focus upon the effects of MEG 
thermal aging on oxygen scavenging performance. Trials are therefore also performed in fresh MEG to illustrate the difference between thermally aged and fresh MEG on the erythorbic acid performance. Additionally, this work will investigate the effect of different salinity levels, $\mathrm{pH}$ levels, and dosage rates on erythorbic acid performance.

\subsection{Erythorbic Acid as an Oxygen Scavenger}

Erythorbic acid, commonly known as a stereoisomer of ascorbic acid (vitamin C), plays a significant role in the human body and food industries. It is widely used as a supplement, additive, preservative, and an antioxidant in processed foods (Abbadi et al., 2003; Barrita and Sánchez, 2013; Kramarenko et al., 2006). In food applications, many investigations have been performed to evaluate the use of erythorbic acid as an oxygen scavenger/antioxidant, including the use of different catalysts and reaction conditions (Amjad, 2010; Crovetto et al., 2011; Elmore, 2005; Kramarenko et al., 2006; Suman et al., 2005). Kramarenko et al. (2006) reported that the reaction of erythorbic acid occurs rapidly with singlet oxygen to form hydrogen peroxide. The general chemical reaction of erythorbic acid with oxygen molecules as suggested by Nimse and Pal (2015) is illustrated in Fig. 2. The mechanism of oxygen consumption is typically initiated by neutralizing erythorbic acid using hydroxylamine compounds such as diethylhydroxylamine (DEHA), hydroquinone, and diethylaminoethanol (DEAE) to form the ascorbate ion $\left(\mathrm{AscH}^{-}\right)$(Christensen and Steimel, 1990; Crovetto et al., 2011; Nimse and Pal, 2015; Pischetsrieder et al., 1995; WENNER, 1949).

The erythorbic acid is a stereoisomer of ascorbic acid (Kundu and Seiersten, 2017). Meanwhile, oxidation of erythorbate/ascorbate ion is an electron transfer reaction. Therefore the scavenging mechanism has expected following the same oxidation pathways of ascorbic acid (Nimse and Pal, 2015). Nimse and Pal (2015) demonstrated that the ascorbate ions are capable of losing an electron to produce an ascorbate radical (ȦscH). This ascorbate radical initiates the oxygen removal through a series of internal chemical reactions (Abbadi et al., 2003; Kundu and Seiersten, 2017; Nimse and Pal, 2015). Furthermore, Christensen and Steimel (1990) and Colton and Gilbert (2007) mentioned that the presence of transition metal ions such as $\mathrm{Mn}^{2+}, \mathrm{Ni}^{2+}$, and $\mathrm{Cu}^{2+}$ might improve ascorbic acid (hence, also erythorbic acid) scavenging performance. In such systems, the transition metals promotes the formation of the erythorbic acid radical through improved electron transfer (Fridovich, 1978; Ikari, 1997; Kundu and Seiersten, 2017; Salasi et al., 2017; Wilson et al., 1995). Various researchers have also concluded that the oxidized erythorbate/ascorbate converts to a more stable structure at the end of the reaction referred to as dehydroascorbic/dehydroerythorbic acid (Barrita and Sánchez, 2013; Elmore, 2005; Harris, 2010; Nimse and Pal, 2015). To date, the performance of erythorbic acid within MEG solutions has undergone limited investigation. Furthermore, there is a lack of literature investigating how oxygen scavengers perform within MEG regeneration plants under field conditions. This lack of information makes it difficult to evaluate the performance of erythorbic acid under field conditions and limits its applicability for use within industrial MEG regeneration and natural gas systems as an oxygen scavenger due to lack of conclusive proof evidence of performance. 
<smiles>O=C1O[C@H]([C@H](O)CO)C(O)=C1O</smiles>

Erythorbate<smiles>CCN(CC)CCO</smiles>

Erythorbate Radical<smiles>O=C1O[C@H]([C@H](O)CO)C([O-])=C1O</smiles>

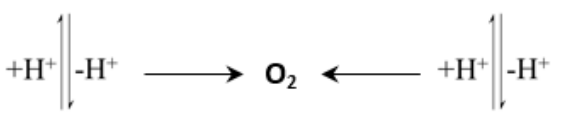

Dehydroerythorbate<smiles>O=C1O[C@H]([C@H](O)CO)C([O-])=C1[O-]</smiles>

Fig. 2. Proposed mechanism of radical scavenging activity of ascorbic acid (Nimse and Pal, 2015)

\subsection{The Relationship between Diethylaminoethanol (DEAE), Mineral Ions and Erythorbic Acid}

Several studies investigated the chemical reaction of DEAE with erythorbic acid (Andrews, 1983; Elmore, 2005; Pischetsrieder et al., 1995). It has been reported that the interaction of DEAE with erythorbic acid can enhance oxygen removal in the food industry (Abbadi et al., 2003; Amjad, 2013; Silberberg, 2006). Christensen and Steimel (1990) stated that hydroxylamine compounds have a catalytic effect on the erythorbic acid reaction. Conversely, Crovetto et al. (2011) and Amjad (2010) concluded that the use of DEAE in other industries was limited to combating corrosion in steam boilers by neutralizing condensate $\mathrm{pH}$. However, Kundu and Seiersten (2017) and Christensen and Steimel (1990) recommended using DEAE instead of NaOH or MDEA due to significant improvement in oxygen scavenging performance of erythorbic acid via the scavenging reaction described by Fig. 2. Once added to the erythorbic acid solution, the DEAE neutralises the erythorbic acid to form its conjugate based erythorbate (Christensen and Steimel, 1990; Harris, 2010; Kundu and Seiersten, 2017).

However, it is still unclear how the erythorbate ion will react with mono and divalent mineral salt ions introduced via formation water. Furthermore, erythorbic acid has been observed to undergo reactions with scale products including calcium carbonate to form calcium erythorbate (Ahrens, 1971; Schreur, 1981). A wide range of minerals will typically be present in the formation water, which may lead to the formation of scale such as calcium carbonate, calcium sulfate and barium sulfate depending on the conditions of temperature and in some instances, the pH (Baraka-Lokmane et al., 2012; Halvorsen et al., 2007; Pojtanabuntoeng et al., 2017).

\subsection{Equipment and Chemicals Used}

The bench-scale oxygen scavenger testing conducted within this study was performed using four custom-made glass testing cells fitted with airtight lids as depicted by Fig. 3. The testing cells incorporated an InPro 4800i pH 
probe and InPro 6850i polarographic dissolved oxygen (DO) sensor supplied by Mettler Toledo. The Mettler Toledo InPro 6850i DO sensor has an oxygen detection range of $6 \mathrm{ppb}$ to saturation with an accuracy of $\pm 1 \%$. The $\mathrm{pH}$ and DO sensors were connected directly to a Mettler Toledo M800 process measurement system to allow continuous monitoring of system conditions as well as a direct recording of all process data to a computer via USB connection.

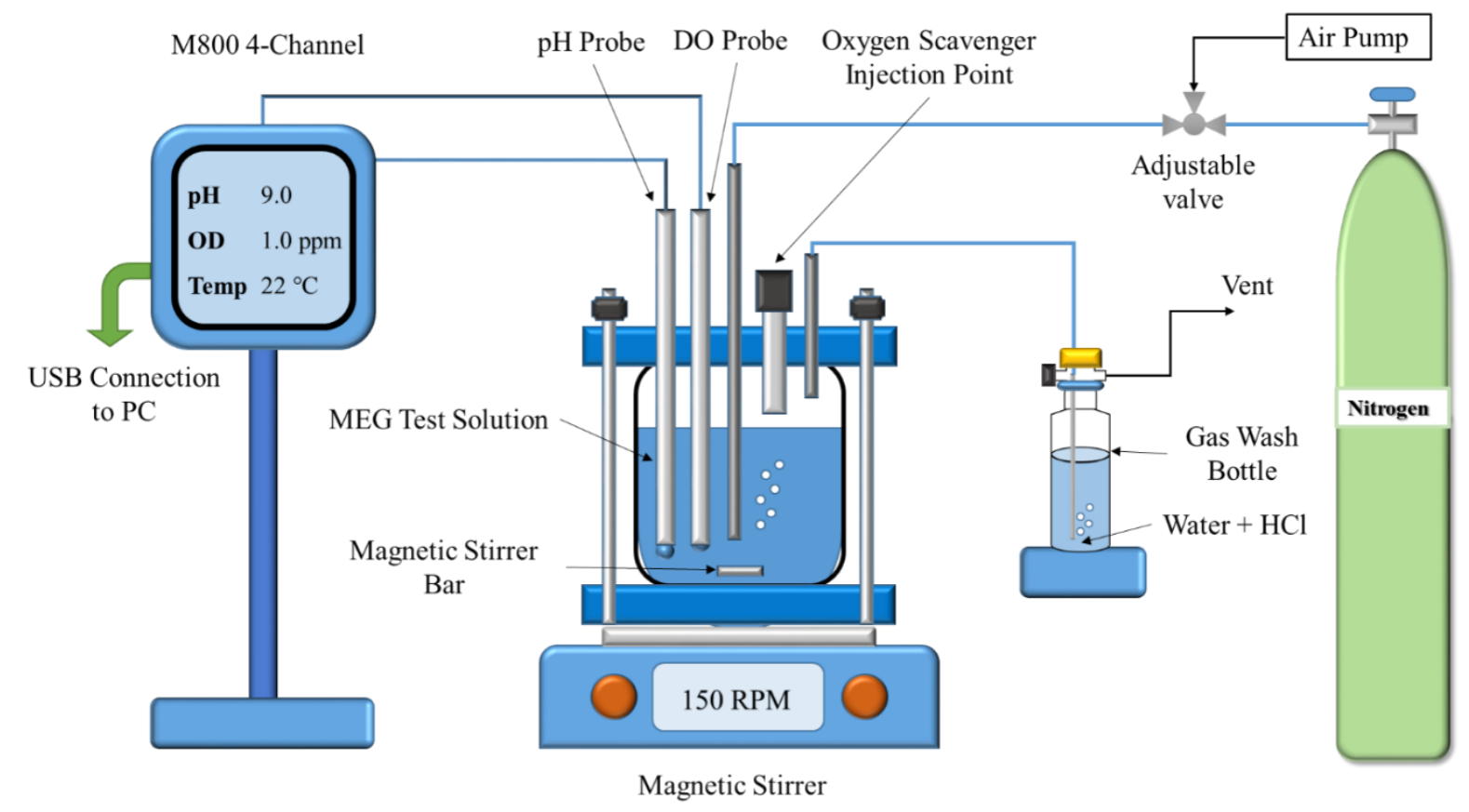

Fig. 3. Bench Scale Oxygen Scavenger Experimental apparatus

Furthermore, each testing cell was fitted with a rubber injection port to allow the injection of the oxygen scavenger solution via a syringe while preventing oxygen intrusion during experimental trials. A retractable stainless steel tube was implemented into the test cell to allow sparging of the test solution with nitrogen or air to achieve the desired starting DO concentration. In addition, the retractable design of the tube enabled continuous sparging of ultra-high purity nitrogen (>99.999 mol\%, supplied by BOC) to be applied within the headspace of the testing cell during operation to minimize oxygen intrusion. To prevent over pressurization of the test system, a gas outlet tube was attached to each cell and connected to a gas wash bottle to avoid flow reversal back into the test cell.

The erythorbic acid oxygen scavenger evaluated within this study was supplied by Sigma Aldrich at a purity greater than $99.0 \%$. The specific erythorbic acid oxygen scavenger composition was developed by IFE (Kundu and Seiersten, 2017) for its potential use within MEG regeneration systems and is outlined in Table 1. The diethylaminoethanol (DEAE) component of the oxygen scavenger was sourced from Sigma Aldrich at a purity greater than $99.5 \%$ and was used to neutralize the erythorbic acid to make erythorbate. Manganese chloride was used to catalyze the oxygen scavenger reaction and was supplied by Sigma Aldrich as $\mathrm{MnCl}_{2} .4 \mathrm{H}_{2} \mathrm{O}$ at a purity greater than $99.0 \%$. All testing was conducted within MEG solution supplied by Chem-Supply. Where the oxygen scavenger was tested within TAL-MEG, the MEG was thermally aged for 10 cycles using a MEG regeneration pilot plant operated by the Curtin Corrosion Engineering Industry Centre (CCIEC) (AlHarooni et 
al., 2017; Zaboon et al., 2017). The MEG was cycled through the distillation system and exposed to temperatures between $125-135^{\circ} \mathrm{C}$ to produce TAL-MEG and subsequently reclaimed to remove any salt content.

Table 1. Evaluated erythorbic acid based oxygen scavenger (Kundu and Seiersten, 2017)

\begin{tabular}{|c|c|c|}
\hline Component & Concentration (wt. \%) & Component Purity (\%) \\
\hline Erythorbic Acid & 17 & 99.0 \\
\hline Diethylaminoethanol (DEAE) & 25 & 99.5 \\
\hline Manganese Chloride $\left(\mathrm{MnCl}_{2} \cdot 4 \mathrm{H}_{2} \mathrm{O}\right)$ & 0.5 & 99.0 \\
\hline Water & 57.5 & Distilled water de-oxygenized with $\mathrm{N}_{2}$ \\
\hline
\end{tabular}

\section{0 pH calibration procedure of TAL-MEG solutions}

The $\mathrm{pH}$ measured in each test was corrected continuously by adding a deviation factor that appeared due to the interference of the liquid junction potential of the $\mathrm{pH}$ electrode with the presence of MEG and brine solution (Sandengen et al., 2007). This bias was calibrated by the model developed by Sandengen et al. (2007).

$$
\begin{aligned}
& \Delta \mathrm{pH}_{\mathrm{MEG}}=0.416 \mathrm{w}-0.393 w^{2}+0.606 \mathrm{wt}^{3} \ldots 1 \\
& \mathrm{pH}_{\text {corrected }}=\mathrm{pH}_{\text {measured }}+\Delta \mathrm{pH}_{\text {MEG }} \quad \ldots 2
\end{aligned}
$$

Where wt denotes the weight fraction of TAL-MEG solution.

\subsection{Experimental Methodology}

Bench-scale oxygen scavenger evaluation was performed using the experimental set-up depicted in Fig. 3. Evaluation of oxygen scavenger performance was conducted within $85 \%$ wt. TAL-MEG solution to simulate its performance within downstream MEG injection systems following the regeneration process. The primary tests outlined within this study were conducted using TAL-MEG to replicate operational conditions found during field operation. To assess the performance of erythorbic acid as a potential oxygen scavenger for MEG service, its performance was evaluated under a range of conditions including varying $\mathrm{pH}$, starting oxygen concentration, salinity, and oxygen scavenger dosage rate. Testing was conducted using three pH levels: 6, 9 and 11, to identify the influence of solution $\mathrm{pH}$ upon oxygen removal efficiency.

The two starting oxygen concentrations studied included $1000 \mathrm{ppb}$ and saturation $(\sim 7500 \mathrm{ppb})$, which represents varying degrees of oxygen content that may be experienced in field operations. To evaluate the efficacy of the erythorbic acid oxygen scavenger solution, two different oxygen scavenger dosage rates (refer to Table 2) were utilized to aid in optimization of dosage requirements in the field. The dosage rate utilized within this study is based upon the weight concentration (ppm) of the erythorbic acid ion (erythorbate) after dissociation within the solution has occurred. Full dissociation of the erythorbic acid was expected during testing through the neutralization reaction with diethylaminoethanol (DEAE) (Christensen and Steimel, 1990).

Additionally, four typical MEG solutions with varying contamination levels of mineral salts and organic acid were used in the oxygen scavenger trials, to assess erythorbic acid performance under real field conditions. These four solutions included fresh MEG, TAL-MEG without mineral salt or organic acids (representing initial operation with uncontaminated fluids), TAL-MEG without mineral salt but with a low content of organic acids (representing operation prior to formation water breakthrough), and TAL-MEG with high content of mineral salt 
as well as presence of organic acids (representing operation following formation water breakthrough). Furthermore, weight fraction of TAL-MEG solution was measured by using Al Helal et al. (2018) models to ensure the concentration of TAL-MEG mixture was within the proposed concentrations. The compositions of the fresh MEG and three TAL-MEG solutions are outlined in Table 3.

Prior to the lean MEG solution tests, the solution was sparged with either nitrogen or air to reach the required starting oxygen concentration of $1000 \mathrm{ppb}$ or $>7500 \mathrm{ppb}$. Simultaneously during the sparging process, the solution $\mathrm{pH}$ was adjusted using either sodium hydroxide or hydrochloric acid solution to adjust the $\mathrm{pH}$ to the desired starting point of 6,9 or 11 . Once the required starting oxygen concentration and $\mathrm{pH}$ were reached, the retractable sparging tube was repositioned into the headspace of the testing cell and a nitrogen blanket produced to prevent oxygen ingress. The erythorbic acid oxygen scavenger solution was then injected into the MEG solution through the rubber injection port, and the recording function of the M800 system commenced using the DO and pH probes discussed in Section 4.0. Recording of the oxygen removal response of the erythorbic acid was conducted over a four-hour period to assess its ability to reach an oxygen concentration below 20ppb. An oxygen concentration below 20ppb within a four-hour time frame was set as the target by a third-party oil and gas company for whom the tests were conducted for based upon their system requirements.

Table 2. Erythorbic Acid Dosage Rate

\begin{tabular}{|c|c|}
\hline High Dosage Rate & Low Dosage Rate \\
\hline $200 \mathrm{ppm}^{*}$ & $100 \mathrm{ppm}{ }^{*}$ \\
\hline *Dosage rate based upon erythorbate ion (by weight)
\end{tabular}

Table 3. MEG salinity levels*

\begin{tabular}{|c|c|c|c|c|c|}
\hline \multicolumn{2}{|c|}{ Salts, ppm } & Fresh MEG & $\begin{array}{c}\text { Aged MEG } \\
\text { No Salt } \\
\text { (Initial operation) } \\
\end{array}$ & $\begin{array}{c}\text { Aged MEG } \\
\text { Low Organic Acids } \\
\text { (Condensed Water Only) }\end{array}$ & $\begin{array}{c}\text { Aged MEG } \\
\text { High Salt } \\
\text { (With Formation Water) }\end{array}$ \\
\hline \multicolumn{2}{|c|}{$\mathrm{Na}$} & 0 & 0 & 0 & 7724.72 \\
\hline \multicolumn{2}{|c|}{$\mathrm{K}$} & 0 & 0 & 0 & 28.35 \\
\hline \multicolumn{2}{|c|}{$\mathrm{Ca}$} & 0 & 0 & 0 & 43.65 \\
\hline \multicolumn{2}{|c|}{$\mathrm{Mg}$} & 0 & 0 & 0 & 1.95 \\
\hline \multicolumn{2}{|c|}{$\mathrm{Fe}$} & 0 & 0 & 0 & 0.72 \\
\hline \multicolumn{2}{|c|}{$\mathrm{Sr}$} & 0 & 0 & 0 & 3.645 \\
\hline \multicolumn{2}{|c|}{$\mathrm{Ba}$} & 0 & 0 & 0 & 3.105 \\
\hline \multicolumn{2}{|c|}{$\mathrm{Li}$} & 0 & 0 & 0 & 0 \\
\hline \multicolumn{2}{|c|}{$\mathrm{Cl}$} & 0 & 0 & 0 & 11641.75 \\
\hline \multicolumn{2}{|c|}{$\mathrm{HCO} 3$} & 0 & 0 & 0 & 87 \\
\hline \multicolumn{2}{|c|}{ SO4 } & 0 & 0 & 0 & 23.55 \\
\hline \multicolumn{2}{|c|}{ Formic Acid } & 0 & 0 & 0 & 0 \\
\hline \multicolumn{2}{|c|}{ Acetic acid } & 0 & 2 & 25.5 & 462.90 \\
\hline \multicolumn{2}{|c|}{ Propanoic acid } & 0 & 0.1 & 1.98 & 44.25 \\
\hline \multicolumn{2}{|c|}{ Butanoic acid } & 0 & 0.5 & 3.345 & 54.30 \\
\hline \multirow{2}{*}{$\begin{array}{c}\text { Total } \\
\text { Salinity }\end{array}$} & ppm & 0 & 2.6 & 30.825 & 20119.90 \\
\hline & gm/L & 0 & 0.0116 & 0.0337 & 22.00 \\
\hline
\end{tabular}

*The salinity level were analysed by using inductively coupled plasma mass spectrometry (ICP-MS) 


\subsection{Results and Discussion}

\subsection{Effect of MEG Thermal Aging upon Erythorbic Acid Oxygen Scavenging Performance}

Four sets of experiments were carried out at $\mathrm{pH} 9$ by using two solutions of fresh and TAL-MEG (No salts) and the low and high dosage rates of the erythorbic acid oxygen scavenger listed in Table 3. The testing was conducted to assess the influence of TAL-MEG upon erythorbic acid oxygen scavenger performance. For each test, the initial oxygen concentration in the MEG solution was adjusted to approximately 1000ppb to simulate industrial field conditions due to oxygen contamination (Crovetto et al., 2011; Kundu and Seiersten, 2017). The performance of the erythorbic acid oxygen scavenger was significantly affected by the thermal aging of MEG (when compared to fresh MEG) as shown by Fig. 4. For both the high and low dosage rates of erythorbic acid, it was observed that TAL-MEG reduced the oxygen removal rate. The time required to reduce the oxygen content to below $20 \mathrm{ppb}$ was 170 minutes (Fig. 4); while in fresh MEG $\mathrm{O}_{2}$ levels reduced to below 20ppb within 100 minutes.

The results of the tests performed suggest that to attain comparable oxygen scavenger performance under field conditions were TAL-MEG is commonly used, a much longer residence time of the oxygen scavenger is required for TAL-MEG leading to increased corrosion potential inside transport pipelines if sufficient time is not provided. It was concluded that the effects of aged MEG products might lower the performance of the erythorbic acid oxygen scavenger. Therefore, it is recommended that future testing of oxygen scavengers for use in MEG systems be implemented in TAL-MEG and not fresh MEG to provide a more accurate representation of their assessment under realistic field conditions.

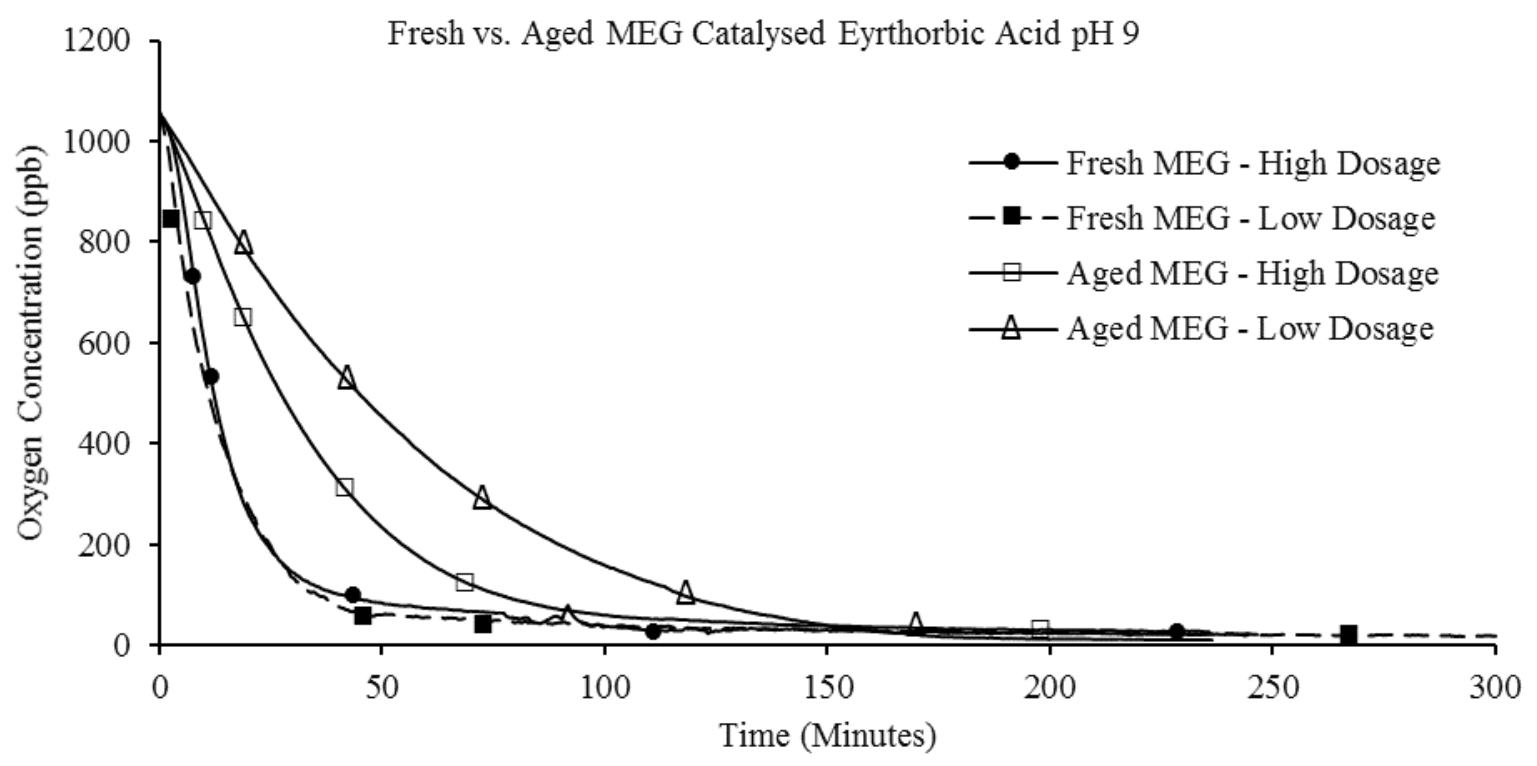

Fig. 4. Effect of MEG Thermal Aging upon Oxygen Scavenger Performance

\subsection{Effect of Organic Acids on Erythorbic Acid Oxygen Scavenging Performance}

Thermally degraded MEG and produced water contain acidic products such as formic acid, acetic acid, oxalic acid, and glycolic acid (AlHarooni et al., 2016; Rossiter et al., 1985). These acids tend to accumulate in the closed glycol loop over time. To evaluate the influence of organic acids on the performance of erythorbic acid as 
an oxygen scavenger, four sets of tests using fresh MEG were conducted with various acetic acid concentrations ranging from 0 to $1000 \mathrm{ppm}$, where the $\mathrm{pH}$ level was maintained at 9. Acetic acid was used to investigate the effects of organic acids as it represents the majority of organic acids experienced in formation water (Daniels et al., 2014; Halvorsen et al., 2007; Pojtanabuntoeng et al., 2017; Tran et al., 2013). The results illustrated in Fig. 5 showed no significant effect of acetic acid on the erythorbic acid oxygen scavenger performance at $\mathrm{pH} 9$ up to 1000ppm. As shown in Fig. 6, The majority of acetic acid will be present as its conjugate base, acetate at a pH of 9 , therefore it can be concluded that the presence of acetate did not negatively influence the performance of erythorbic acid as an oxygen scavenger (Brown, 2009).

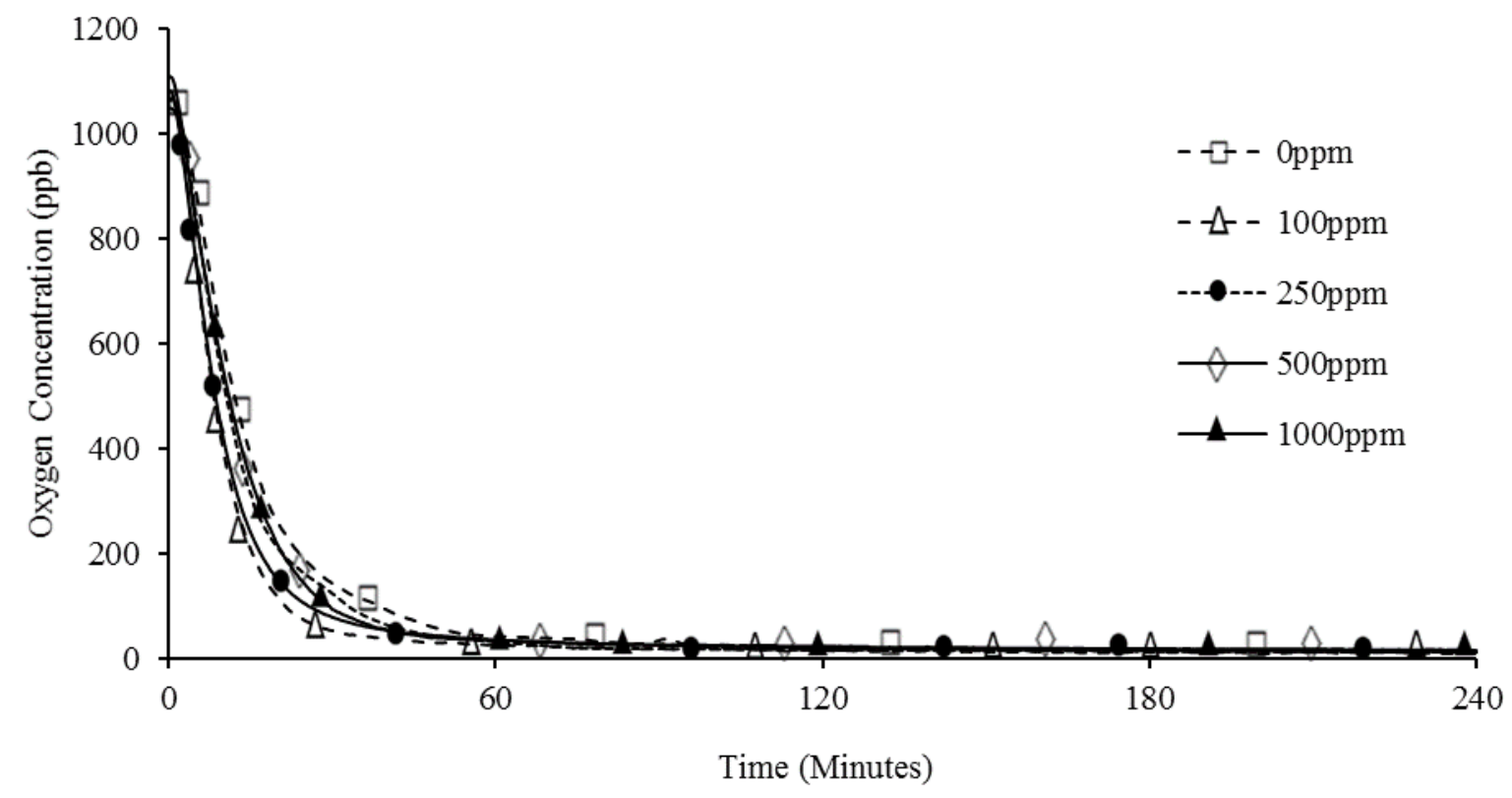

Fig. 5. Effect of Acetic Acid Concentration on erythorbic acid Oxygen Scavenger Performance (at $\mathrm{pH}=9$ ) within Fresh MEG

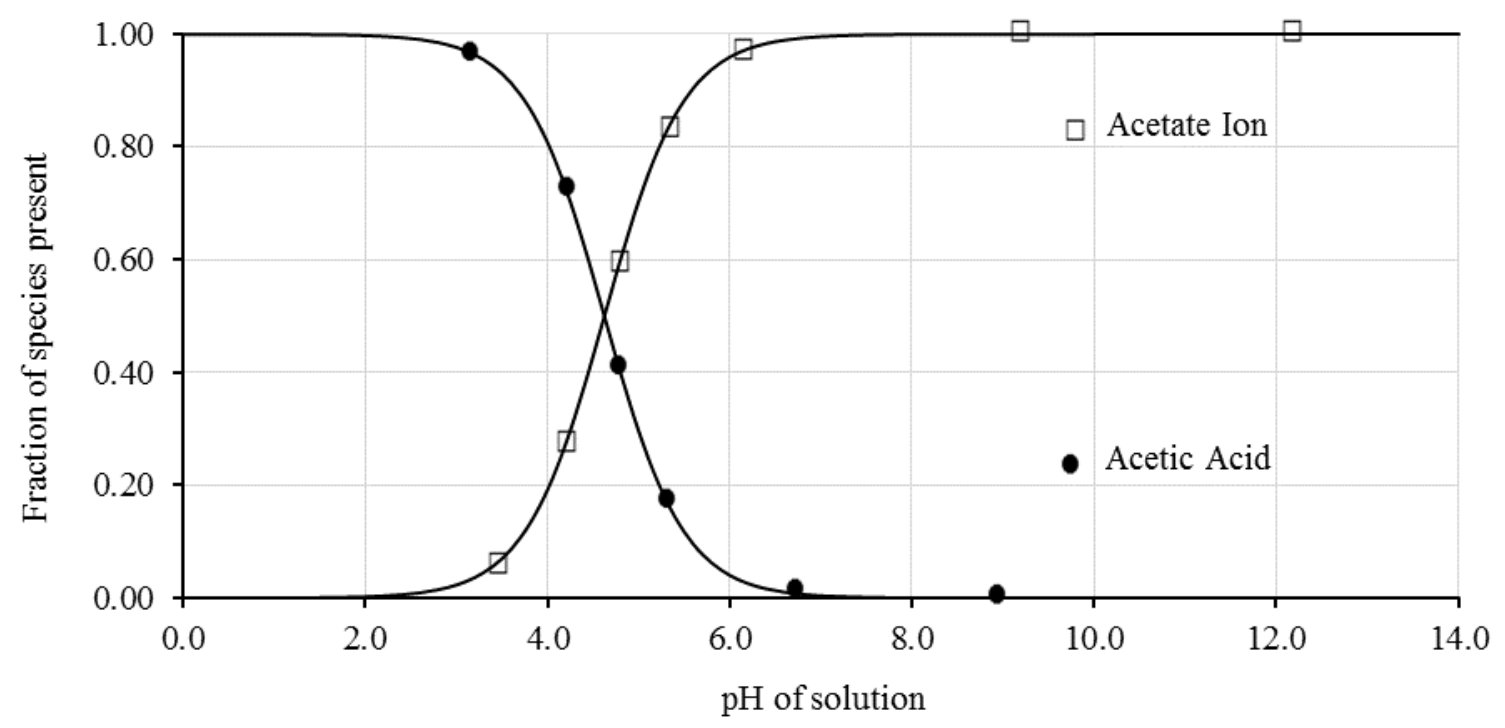

Fig. 6. Relationship between pH of Solution and Dissociation Status of Acetic Acid (Brown, 2009) 


\subsection{Evaluation of Erythorbic Acid Performance under Field Conditions (1000ppb and Saturation)}

The influence of $\mathrm{pH}$ was investigated to evaluate the performance of erythorbic acid oxygen scavengers within TAL-MEG using the three MEG solution compositions tested: MEG-low salts, MEG-low organic acids (condensed water only) and MEG-high salts (with formation water). Three sets of experiments were conducted using the low and high dosage rates of erythorbic acid at $\mathrm{pH}$ of 6,9 and 11 as outlined in Table 3. Furthermore, each set of experiments was conducted using both $\sim 7500 \mathrm{ppb}$ (saturation) oxygen concentration to evaluate the effect of erythorbic acid at high oxygen contents and 1000ppb representing typical oxygen contamination levels in the industry.

The increase in $\mathrm{pH}$ from 6 to 11 (MEG-low salts) improved the oxygen scavenging performance of erythorbic acid within TAL-MEG. The results generated align with literature data which suggests that the performance of erythorbic acid is improved at high pH (Amjad, 2013; Christensen and Steimel, 1990; May, 1989). Under all salinity conditions tested, the poor performance of erythorbic acid was observed at $\mathrm{pH} 6$ with erythorbic acid failing to reach the desired 20ppb oxygen concentration from both saturation and 1000ppb (refer to Figs. 7-12). The generated results are in line with the conclusions of Kundu and Seiersten (2017) for pH 6 within fresh MEG. The poor performance of erythorbic acid at low $\mathrm{pH}$ is due to the initial step of the oxygen scavenging reaction where erythorbic acid is neutralized to erythorbate being either inhibited or reversed (refer to Fig. 2). The different salt levels and low or high dosage rates had no significant effects on the final performance, as shown in Figs.10-12.

In contrast to $\mathrm{pH} \mathrm{6,} \mathrm{erythorbic} \mathrm{acid} \mathrm{demonstrated} \mathrm{consistently} \mathrm{strong} \mathrm{performance} \mathrm{at} \mathrm{pH} 9$ and was capable of successfully reducing the oxygen concentration from both saturation and 1000ppb to below 20ppb (refer to Figs. 7-12). However, a noticeable difference in oxygen removal rate was observed between the high and low dosage rates, with the low rate typically requiring an additional hour to achieve parity with the high dosage rate. The dependency on dosage rate for oxygen removal within MEG solution has been previously demonstrated by Salasi et al. (2017), where a greater dosage rate is often required within MEG compared to water systems. Furthermore, minimal to no impact due to the presence of organic acids and mineral salt ions was observed when compared to low salt trials (refer to Fig. 8 and Fig. 11) with the minimal impact due to high organic acid concentrations in line with the results in Section 7.2.

At a $\mathrm{pH}$ of 11 the erythorbic acid oxygen scavenger exhibited strong performance and was capable of reducing the dissolved oxygen concentration from both saturation and from 1000ppb to below 10ppb in less than one hour within TAL-MEG, with no influence of mineral ions and organic acid on performance exhibited (refer to Figs. 7-12). In addition, whilst tested at a $\mathrm{pH}$ of 11, due to the fast reaction time the erythorbic acid oxygen scavenger demonstrated near equal performance between the high and low dosage rates tested. As such, whilst operating at high $\mathrm{pH}$ the dosage rate of the oxygen scavenger can be effectively halved with no major implication on oxygen removal performance with a further reduction in dosage rate possible. However during the processing of natural gas, it may not be desirable to operate under such high $\mathrm{pH}$ conditions for the injected lean MEG due to the potential for scale formation if salt-containing formation water is being produced (Bikkina et al., 2012; Kaasa, 1998; Kundu and Seiersten, 2017; Latta et al., 2013). Therefore, the application of erythorbic acid for oxygen removal at $\mathrm{pH} 11$ is only suitable where no formation water is produced or where an appropriate scale inhibitor is used in conjunction to manage the scale risk. 
Catalysed Erythorbic Acid Testing at Saturation

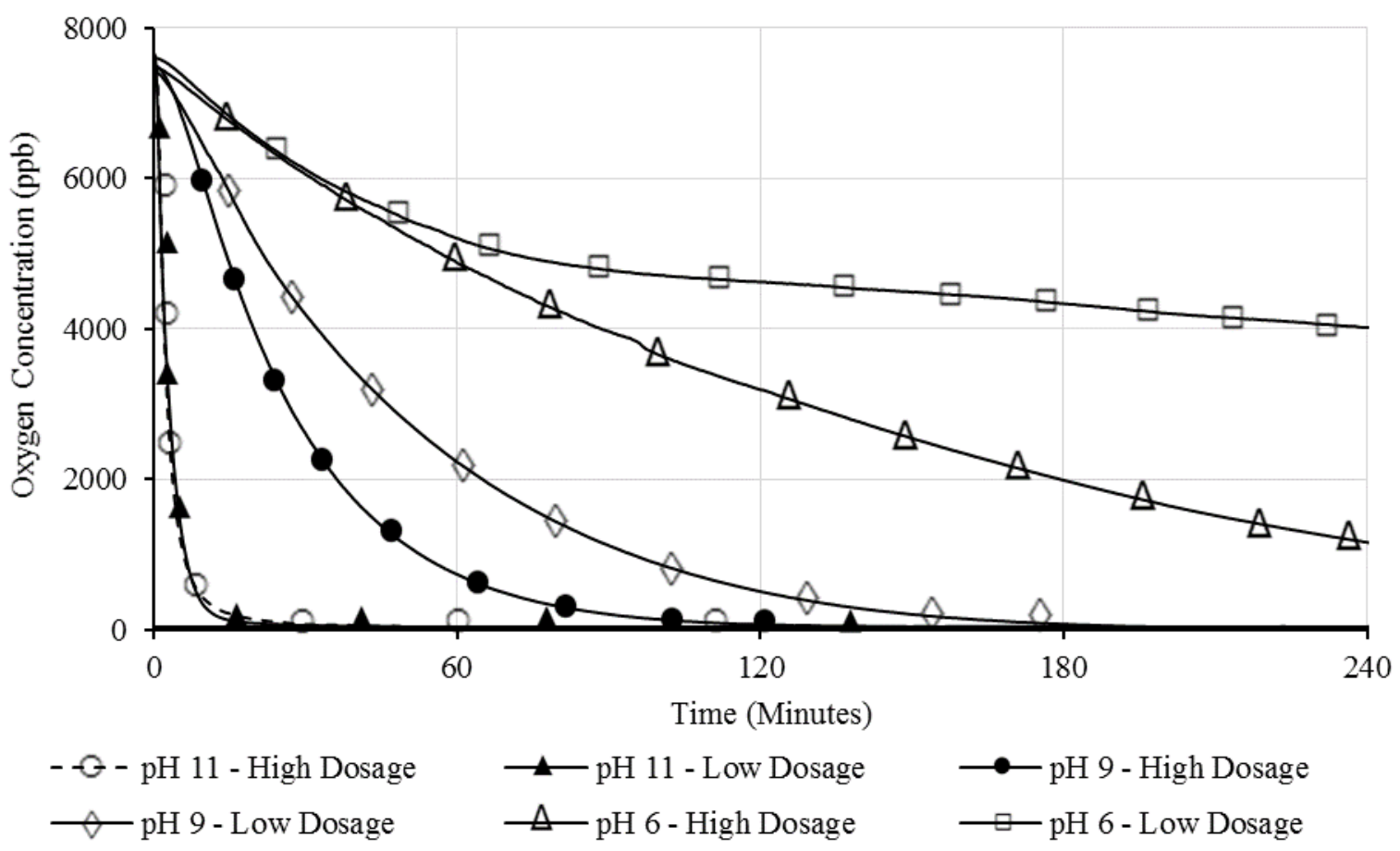

Fig. 7. Effect of pH upon erythorbic acid Performance in MEG No salts TAL-MEG

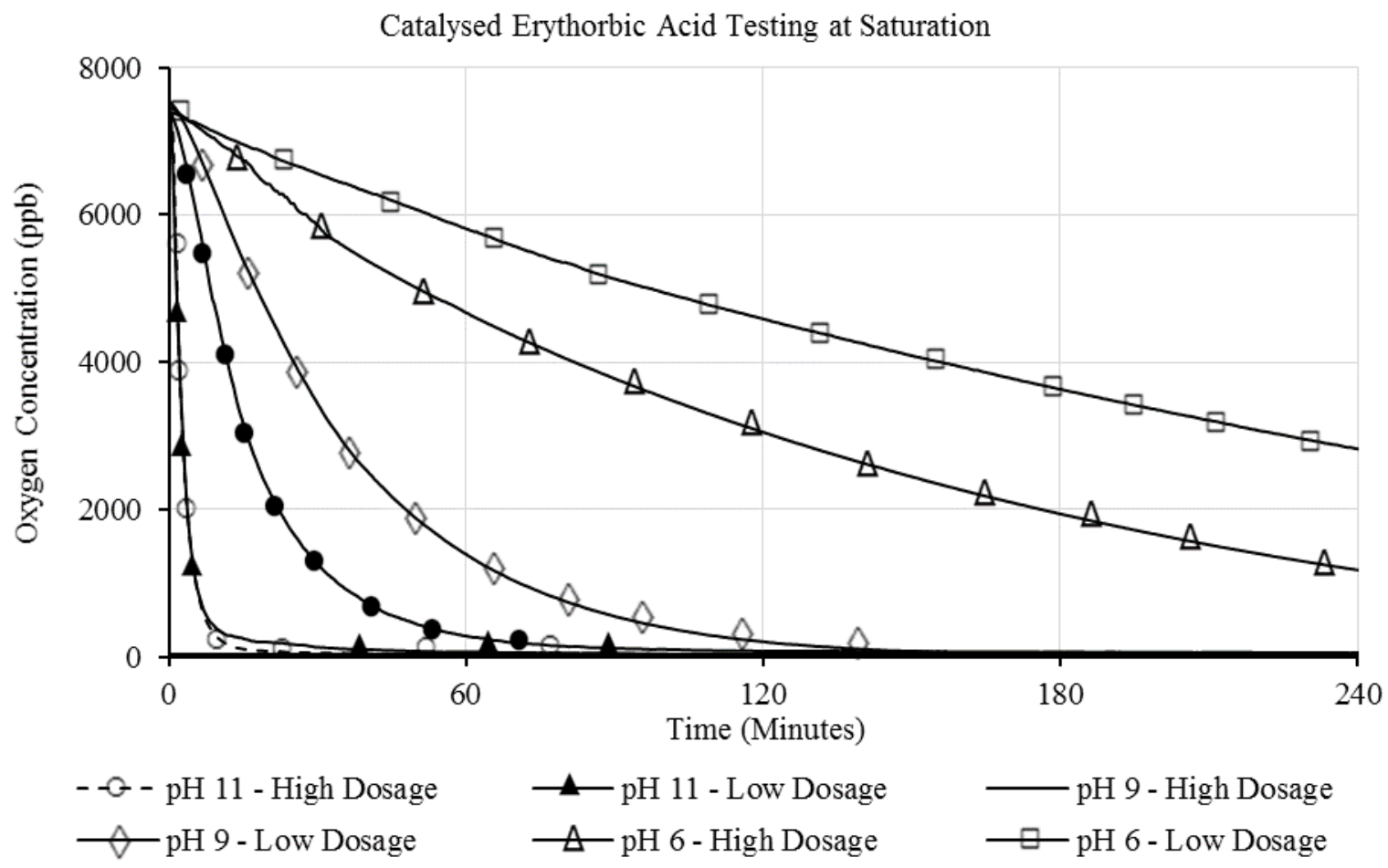

Fig. 8. Effect of $\mathrm{pH}$ upon erythorbic acid Performance in Low Organic Acid TAL-MEG 


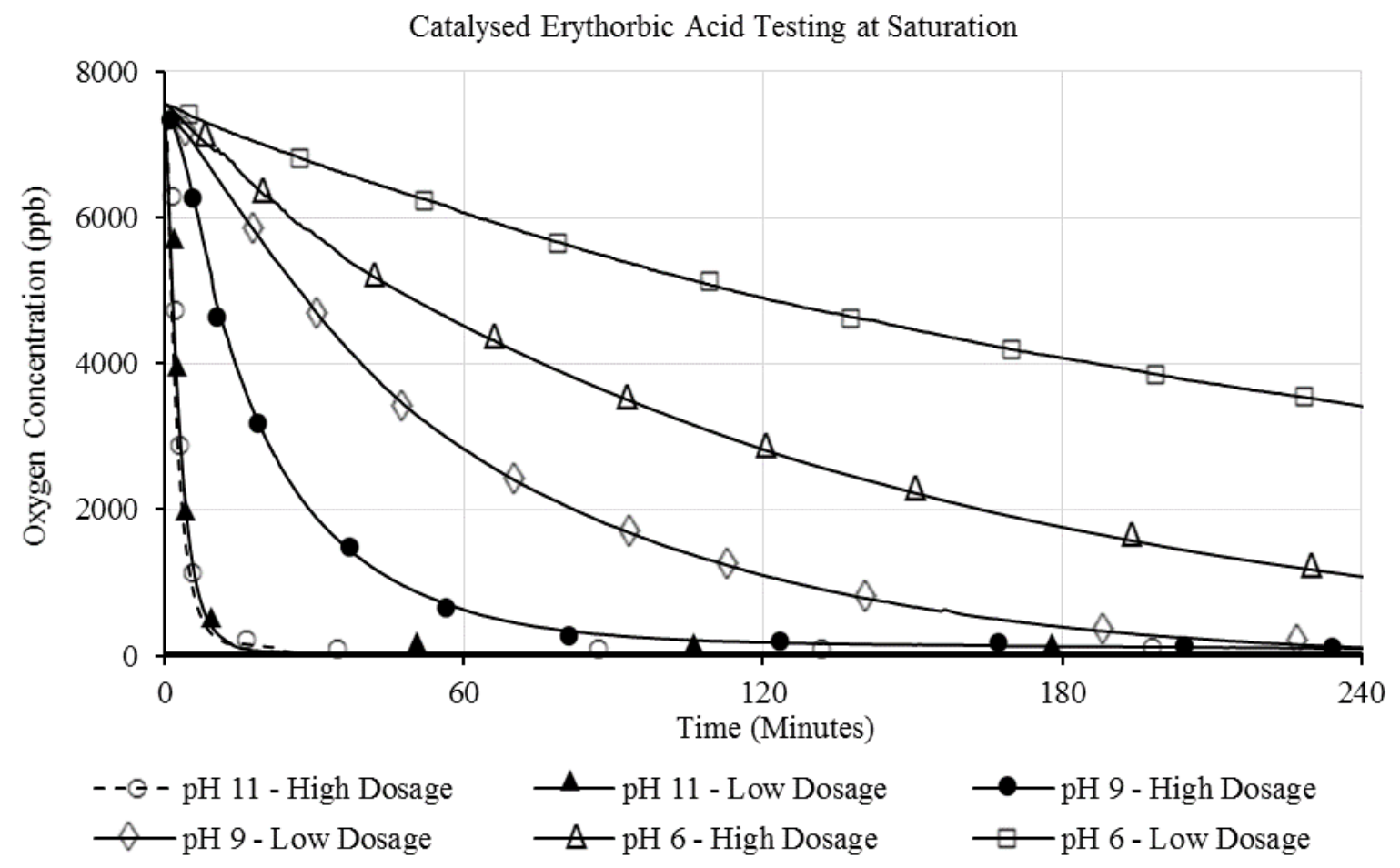

Fig. 9. Effect of pH upon erythorbic acid Performance in High Salinity TAL-MEG

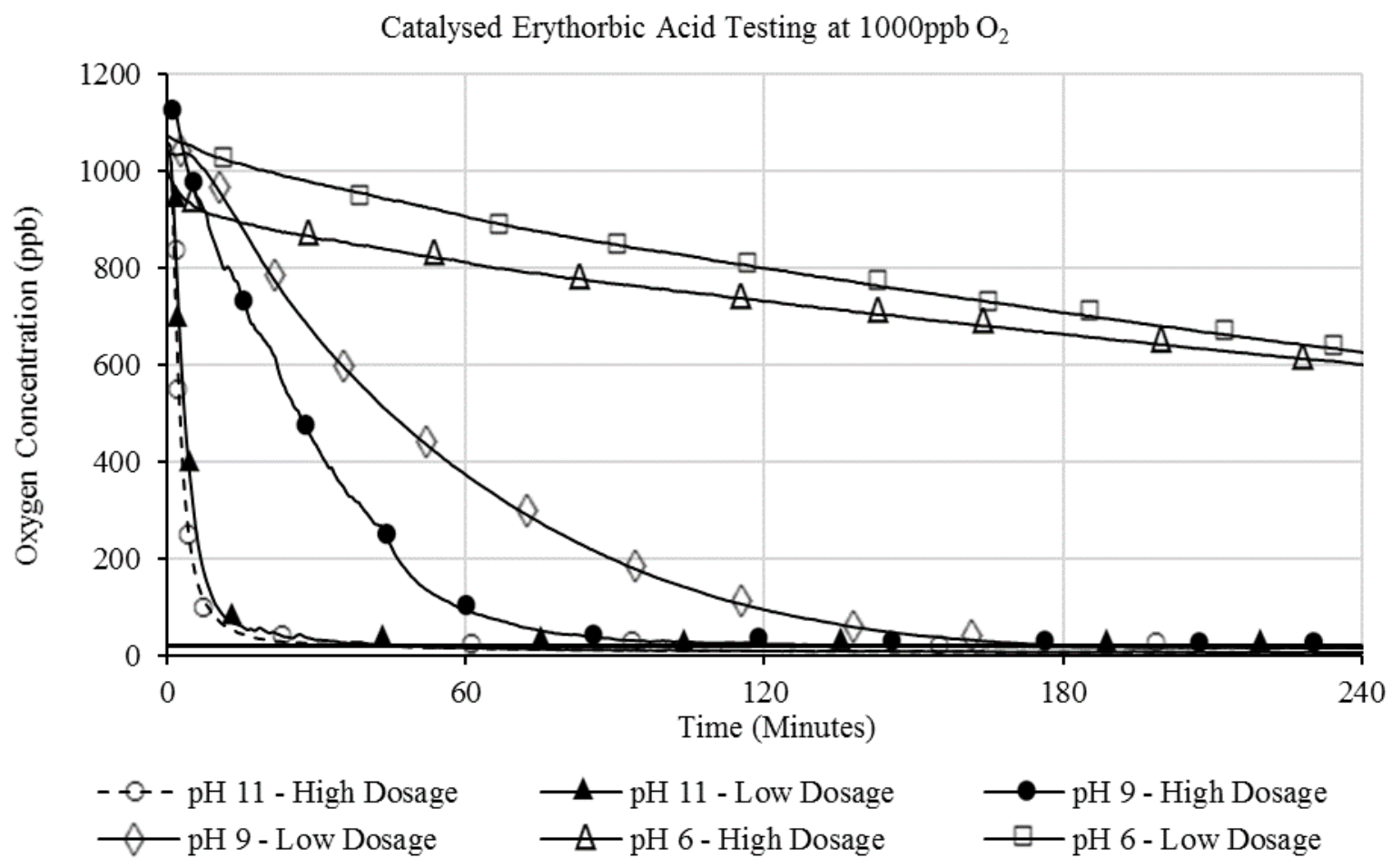

Fig. 10. Effect of $\mathrm{pH}$ upon erythorbic acid Performance in MEG No salts TAL-MEG 
Catalysed Erythorbic Acid Testing at 1000ppb $\mathrm{O}_{2}$

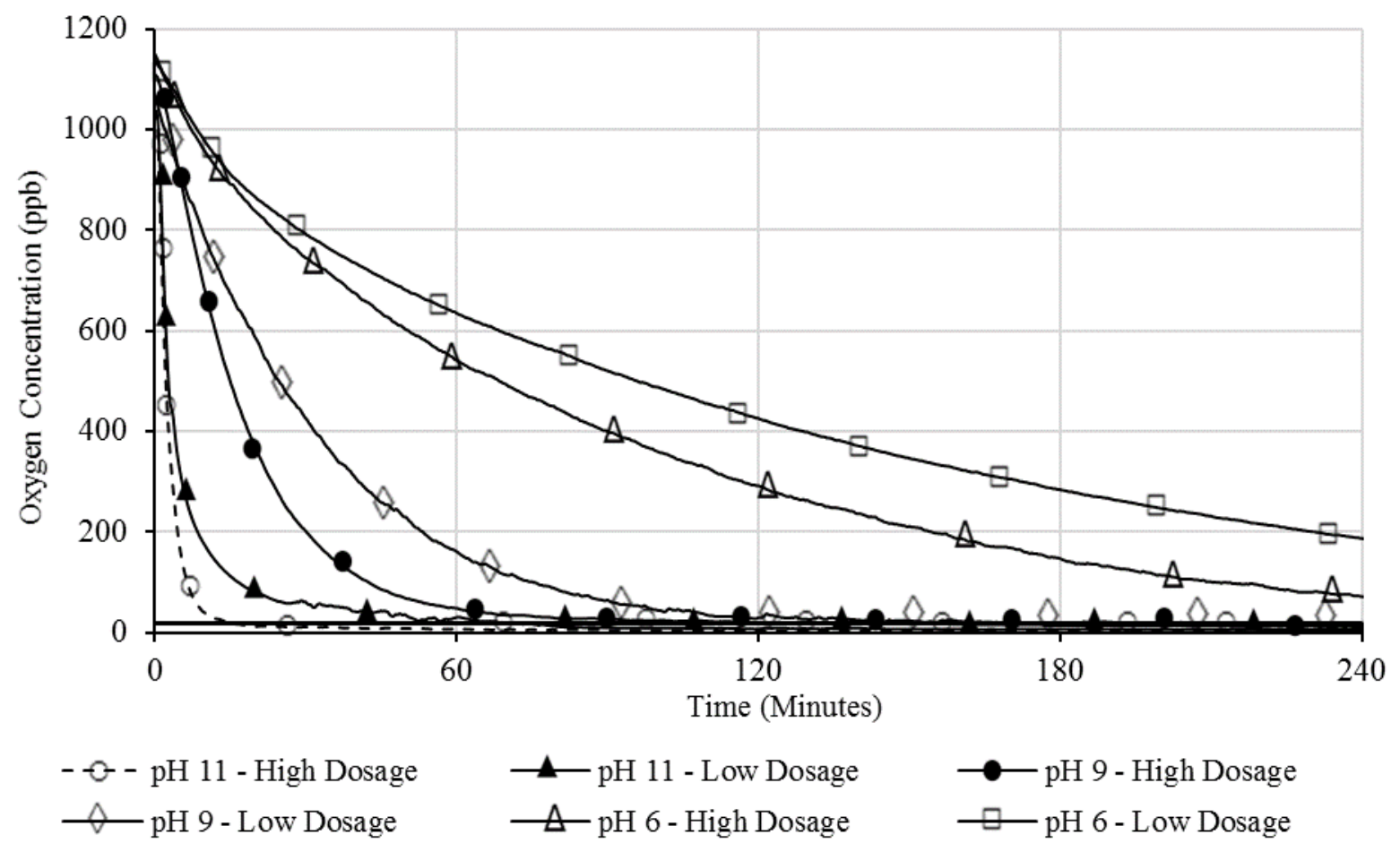

Fig. 11. Effect of pH upon erythorbic acid Performance in MEG-low organic acids (condensed water only) TAL-MEG

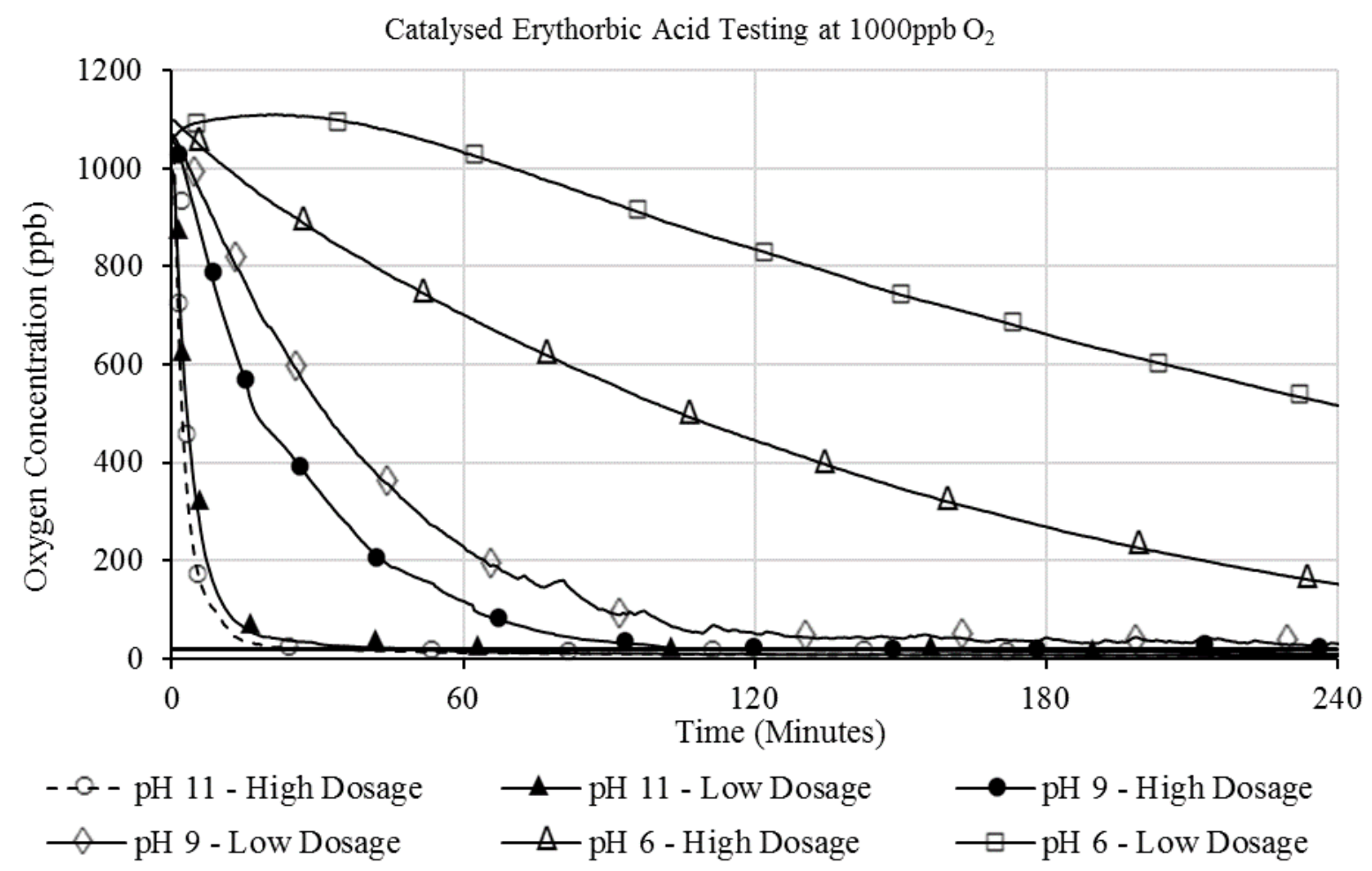

Fig. 12. Effect of $\mathrm{pH}$ upon erythorbic acid Performance in high salts MEG (full formation water) TAL-MEG 


\subsection{Conclusion}

Erythorbic acid as an oxygen scavenger has been extensively recognized for its strong performance as a preservative within the food industry (Barrita and Sánchez, 2013; Kramarenko et al., 2006; May, 1989; Pisoschi et al., 2009; Suman et al., 2005). However, little to no investigation has been performed to assess its applicability for use within the oil and gas industry, specifically under field conditions. The application of erythorbic acid in the oil and gas industry may provide a strong performing non-hazardous alternative to commonly used oxygen scavengers including sulfites to prevent oxygen-based corrosion issues in transportation pipelines and subsea equipment. Therefore, bench-scale evaluation of erythorbic acid has been performed to assess its performance under conditions typically found within industrial MEG regeneration systems including the effects of MEG thermal aging and the presence of common industrial contaminants such as salts and organic acids.

Previous evaluation of erythorbic acid as an oxygen scavenger has been performed within fresh MEG (Kundu and Seiersten, 2017) but may not provide an accurate representation of field use. The performance of erythorbic acid has hence been evaluated within TAL-MEG to confirm its suitability for use within TAL-MEG postregeneration. The results of the testing performed showed a noticeable decrease in oxygen scavenger performance at $\mathrm{pH}$ 9. However, erythorbic acid was still capable of achieving the desired 20ppb oxygen concentration within an acceptable time frame (sub 4 hours). As such, this study strongly suggests that erythorbic acid is suitable for use within TAL-MEG and applicable for use in industrial MEG regeneration systems.

However at a $\mathrm{pH}$ of 6 , erythorbic acid demonstrated poor oxygen removal performance is limiting its applicability at low $\mathrm{pH}$. The reduced performance at $\mathrm{pH} 6$ was attributed to the inability to fully neutralize the erythorbic acid molecule to its conjugate based (erythorbate) a step necessary to initiate the oxygen scavenging mechanism. Conversely, strong oxygen removal performance was demonstrated at pH 9 and 11 with little to no impact observed due to the presence of mineral salt ions typically found in MEG regeneration systems. Furthermore, through the testing conducted it was discovered that the presence of organic acids (acetic) did not have a significant impact on the performance of the tested erythorbic acid oxygen scavenger. Overall, the $\mathrm{pH}$ of the test solution was found to be the primary factor in determining the performance of erythorbic acid as an oxygen scavenger.

\subsection{Acknowledgments}

The authors acknowledge the support of Chevron Australia Pty. Ltd., Curtin Corrosion Engineering Industry Centre (CCEIC) and the WA School of Mines: Minerals, Energy and Chemical Engineering at Curtin University and the Al-Khwarizmi College of Engineering at Baghdad University during the conduction of this study.

\subsection{References}

Abbadi, A., Gotlieb, K., Meiberg, J. and Van Bekkum, H., 2003. New food antioxidant additive based on hydrolysis products of lactose. Green Chemistry, 5(1): 47-51.

Ahrens, G., 1971. Method of preparing high concentration calcium ascorbate reaction products and products produced by same. US Patent App. 3/755,592.

Al Helal, A., Soames, A., Gubner, R., Iglauer, S. and Barifcani, A., 2017. Influence of Magnetic Fields on Calcium Carbonate Scaling in Aqueous Solutions at $150^{\circ} \mathrm{C}$ and 1 Bar. Journal of Colloid and Interface Science. 
Al Helal, A., Soames, A., Gubner, R., Iglauer, S. and Barifcani, A., 2018. Measurement of mono ethylene glycol volume fraction at varying ionic strengths and temperatures. Journal of Natural Gas Science and Engineering, 54: 320-327.

AlHarooni, K., Barifcani, A., Pack, D., Gubner, R. and Ghodkay, V., 2015. Inhibition effects of thermally degraded MEG on hydrate formation for gas systems. Journal of Petroleum Science and Engineering, 135: 608-617.

AlHarooni, K., Gubner, R., Iglauer, S., Pack, D. and Barifcani, A., 2017. Influence of Regenerated Monoethylene Glycol on Natural Gas Hydrate Formation. Energy \& Fuels, 31(11): 12914 12931.

AlHarooni, K. et al., 2016. Analytical Techniques for Analyzing Thermally Degraded Monoethylene Glycol with Methyl Diethanolamine and Film Formation Corrosion Inhibitor. Energy \& Fuels, 30(12): 10937-10949.

Amjad, Z., 2010. The science and technology of industrial water treatment. CRC Press.

Amjad, Z., 2013. Mineral Scales in Biological and Industrial Systems. CRC Press.

Andrews, G.C., 1983. Derivatives of L-ascorbic acid and D-erythorbic acid. US Patent App. $4,368,330$.

Babu, D. et al., 2015. Carbonates precipitation in MEG loops-A comparative study of South Pars and Bass Strait gas fields. Journal of Natural Gas Science and Engineering, 27: 955-966.

Baraka-Lokmane, S. et al., 2012. Prediction of Mineral Scaling in a MEG Loop System of a gas production offshore, SPE International Conference on Oilfield Scale. Society of Petroleum Engineers.

Barrita, J.L.S. and Sánchez, M.d.S.S., 2013. Antioxidant role of ascorbic acid and his protective effects on chronic diseases, Oxidative Stress and Chronic Degenerative Diseases-A Role for Antioxidants. InTech.

Bikkina, C., Radhakrishnan, N., Jaiswal, S., Harrington, R. and Charlesworth, M., 2012. Development of MEG regeneration unit compatible corrosion inhibitor for wet gas systems, SPE Asia Pacific Oil and Gas Conference and Exhibition. Society of Petroleum Engineers.

Brandt, C. and Van Eldik, R., 1995. Transition metal-catalyzed oxidation of sulfur (IV) oxides. Atmospheric-relevant processes and mechanisms. Chemical Reviews, 95(1): 119-190.

Brown, P.W., Galuk, K.G. and Rossiter Jr, W.J., 1987. Characterization of potential thermal degradation products from the reactions of aqueous ethylene glycol and propylene glycol solutions with copper metal. Solar energy materials, 16(4): 309-313.

Brown, T.L., 2009. Chemistry: the central science. Pearson Education.

Christensen, R.J. and Steimel, L.H., 1990. Oxygen scavenger for boiler water and method of use. US Patent App. 4,891,141.

Clifton, J.R., Rossiter, W.J. and Brown, P.W., 1985. Degraded aqueous glycol solutions: pH values and the effects of common ions on suppressing $\mathrm{pH}$ decreases. Solar energy materials, 12(1): 77-86.

Colton, C. and Gilbert, D., 2007. Reactive Oxygen Species in Biological Systems: An Interdisciplinary Approach. Springer Science \& Business Media.

Crovetto, R., Murtagh, E. and Rossi, A.M., 2011. Research evaluation of polyamine chemistry for boiler treatment: Corrosion Protection, CORROSION 2011. NACE International.

Crowe, C., 1985. Evaluation of agents for preventing precipitation of ferric hydroxide from spent treating acid. Journal of petroleum technology, 37(04): 691-695.

Daniels, J.K., Littlehales, I.J., Lau, L. and Linares-Samaniego, S., 2014. Laboratory Methods for Scale Inhibitor Selection for HP/HT Fields, SPE International Oilfield Scale Conference and Exhibition. Society of Petroleum Engineers.

Dugstad, A. and Seiersten, M., 2004. pH-stabilisation, a reliable method for corrosion control of wet gas pipelines, SPE International Symposium on Oilfield Corrosion. Society of Petroleum Engineers.

Elmore, A., 2005. Final report of the safety assessment of L-Ascorbic Acid, Calcium Ascorbate, Magnesium Ascorbate, Magnesium Ascorbyl Phosphate, Sodium Ascorbate, and Sodium Ascorbyl Phosphate as used in cosmetics. International journal of toxicology, 24: 51-111.

Finkbeiner, H. and Bush, J.B., 1968. Oxidation of acetic acid by manganese (III) salts. Discussions of the Faraday Society, 46: 150-157. 
Flaten, E.M. et al., 2015. Impact of Monoethylene Glycol and Fe 2+ on Crystal Growth of CaCO 3, CORROSION 2015. NACE International.

Fridovich, I., 1978. The biology of oxygen radicals. Science, 201(4359): 875-880.

Gui, F., Cong, H., Beavers, J. and Sridhar, N., 2013. Inhibition of Carbon Steel Stress Corrosion Cracking in Fuel Grade Ethanol by Chemical Addition or Oxygen Control: A Feasibility Evaluation, CORROSION 2013. NACE International.

Halvorsen, A.M.K. et al., 2007. The Relationship Between Internal Corrosion Control Method, Scale Control And Meg Handling Of A Multiphase Carbon Steel Pipeline Carrying Wet Gas With CO2 And Cetic Acid, CORROSION 2007. NACE International.

Haque, M.E., 2013. Ethylene glycol regeneration plan: a systematic approach to troubleshoot the common problems. Journal of Chemical Engineering, 27(1): 21-26.

Harris, D.C., 2010. Quantitative chemical analysis. Macmillan.

Ikari, Y., 1997. Composition containing divalent manganese ion. Patent App. 5,618,526.

Ivonye, I., Wang, C. and Neville, A., 2015. The Corrosion of Carbon Steel in the Presence of Monoethylene Glycol (MEG)-Assessing the Influence of an Iron Carbonate Scale, CORROSION 2015. NACE International.

Joosten, M.W., Tier, B., Seiersten, M. and Wintermark, C., 2007. Materials Considerations for MEG (Mono Ethylene Glycol) Reclamation Systems, CORROSION 2007. NACE International.

Kaasa, B., 1998. Prediction of $\mathrm{pH}$, mineral precipitation and multiphase equilibria during oil recovery, Norges teknisk-naturvitenskapelige universitet.

Kan, A., Wu, X., Fu, G. and Tomson, M., 2005. Validation of scale prediction Algorithms at oilfield conditions, SPE International Symposium on Oilfield Chemistry. Society of Petroleum Engineers.

Kan, A.T., Fu, G. and Tomson, M.B., 2003. Effect of methanol and ethylene glycol on sulfates and halite scale formation. Industrial \& engineering chemistry research, 42(11): 2399-2408.

King, C.S., Messenger, B.E., Nemmara, H.V., Zheng, Z.F. and Shihui, Z., 2017. Short contact, elevated temperature meg reclamation. Patent App. 20170015613A1.

Kotronarou, A. and Sigg, L., 1993. Sulfur dioxide oxidation in atmospheric water: role of iron (II) and effect of ligands. Environmental science \& technology, 27(13): 2725-2735.

Kramarenko, G.G., Hummel, S.G., Martin, S.M. and Buettner, G.R., 2006. Ascorbate reacts with singlet oxygen to produce hydrogen peroxide. Photochemistry and photobiology, 82(6): 16341637.

Kundu, S.S. and Seiersten, M., 2017. Development of a non-sulphite oxygen scavenger for monoethylene glycol (MEG) used as gas hydrate inhibitor. Journal of Petroleum Science and Engineering.

Latta, T.M., Seiersten, M.E. and Bufton, S.A., 2013. Flow assurance impacts on lean/rich MEG circuit chemistry and MEG regenerator/reclaimer design, Offshore Technology Conference. Offshore Technology Conference.

Lehmann, M. et al., 2014. Corrosion Inhibitor and Oxygen Scavenger for use as MEG Additives in the Inhibition of Wet Gas Pipelines, Offshore Technology Conference-Asia. Offshore Technology Conference.

Lu, H., Kan, A.T. and Tomson, M.B., 2010. Effects of monoethylene glycol on carbonate equilibrium and calcite solubility in gas/monoethylene glycol/ $/ \mathrm{NaCl} /$ water mixed systems. Spe Journal, 15(03): 714-725.

Mansoori, H., Mirzaee, R. and Mohammadi, A., 2013. Pitting Corrosion Failures of Natural Gas Transmission Pipelines, IPTC 2013: International Petroleum Technology Conference.

May, R.D., 1989. Oxygen removal with carbon catalyzed erythorbate or ascorbate. US Patent App. 4851130A.

Nazzer, C. and Keogh, J., 2006. Advances in glycol reclamation technology, Offshore Technology Conference. Offshore Technology Conference.

Nimse, S.B. and Pal, D., 2015. Free radicals, natural antioxidants, and their reaction mechanisms. Rsc Advances, 5(35): 27986-28006.

Nurmi, D., Overman, J., Erwin, J. and HUDSON, J., 1982. Sulfite Oxidation in Organic Acid Solutions. ACS Publications. 
Olsen, S., 2006. Corrosion Control by Inhibition, Environmental Aspects, and pH Control: Part II: Corrosion Control by pH Stabilization, CORROSION 2006. NACE International.

Pischetsrieder, M., Larisch, B., Mueller, U. and Severin, T., 1995. Reaction of ascorbic acid with aliphatic amines. Journal of agricultural and food chemistry, 43(12): 3004-3006.

Pisoschi, A.M., Danet, A.F. and Kalinowski, S., 2009. Ascorbic acid determination in commercial fruit juice samples by cyclic voltammetry. Journal of Analytical Methods in Chemistry, 2008.

Pojtanabuntoeng, T., Kinsella, B., Ehsani, H. and McKechnie, J., 2017. Assessment of corrosion control by $\mathrm{pH}$ neutralisation in the presence of glycol at low temperature. Corrosion Science.

Rossiter, W.J., Godette, M., Brown, P.W. and Galuk, K.G., 1985. An investigation of the degradation of aqueous ethylene glycol and propylene glycol solutions using ion chromatography. Solar Energy Materials, 11(5-6): 455-467.

Salasi, M., Pojtanabuntoeng, T., Wong, S. and Lehmann, M., 2017. Efficacy of Bisulfite Ions as an Oxygen Scavenger in Monoethylene Glycol (At Least 20 wt\%)/Water Mixtures. SPE Journal.

Sandengen, K., 2006. Prediction of mineral scale formation in wet gas condensate pipelines and in MEG (mono ethylene glycol) regeneration plants, Norwegian University of Science and Technology.

Sandengen, K., Kaasa, B. and Østvold, T., 2007. pH Measurements in Monoethylene Glycol (MEG)+ Water Solutions. Industrial \& engineering chemistry research, 46(14): 4734-4739.

Schreur, C., 1981. Method of making a solid crystalline composition consisting essentially of calcium ascorbate. US Patent App. 4,251,449.

Silberberg, M., 2006. Chemistry: The molecular Nature of Matter and Change. McGraw Hill. New York, NY.

Suman, S. et al., 2005. Effect of erythorbate, storage and high-oxygen packaging on premature browning in ground beef. Meat science, 69(2): 363-369.

Tran, T., Brown, B., Nešić, S. and Tribollet, B., 2013. Investigation of the electrochemical mechanisms for acetic acid corrosion of mild steel. Corrosion, 70(3): 223-229.

WENNER, W., 1949. The reaction of 1-ascorbic and d-isoascorbic acid with nicotinic acid and its amide. The Journal of organic chemistry, 14(1): 22-26.

Wilson, R., Beezer, A.E. and Mitchell, J.C., 1995. A kinetic study of the oxidation of L-ascorbic acid (vitamin C) in solution using an isothermal microcalorimeter. Thermochimica Acta, 264: 27 40.

Yong, A. and Obanijesu, E.O., 2015. Influence of natural gas production chemicals on scale production in MEG regeneration systems. Chemical Engineering Science, 130: 172-182.

Zaboon, S., Soames, A., Ghodkay, V., Gubner, R. and Barifcani, A., 2017. Recovery of monoethylene glycol by distillation and the impact of dissolved salts evaluated through simulation of field data. Journal of Natural Gas Science and Engineering, 44: 214-232. 